\title{
IMPLEMENTASI KNOWLEDGE MANAGEMENT SYSTEM BERBASIS WEBSITE DENGAN MODEL SPIRAL PADA PT. TRANS RETAIL INDONESIA
}

\author{
ENTIS SUTRISNA \\ Staf Pengajar Fakultas Teknik Prodi Teknik Informatika \\ Universitas Pamulang, Tangerang Selatan, Banten \\ Email: sutrisna@gmail.com
}

\begin{abstract}
ABSTRAK
Knowledge Management(KM) didalamnya meliputi penciptaan knowledge, penyimpanan knowledge, pemindahan knowledge dan pengaplikasian knowledge tersebut dalam organisasi untuk menciptakan efektifitas dan efisiensi kerja dengan cara membawa knowledge yang telah ada sebelumnya sebagai dasar pengambilan keputusan dan acuan kerja. PT. Trans Retail Indonesia adalah salah satu perusahaan retail yang belum menerapkan Knowledge Management System (KMS). Persaingan antara peretail sangat lazim dilakukan demi memenangkan persaingan bisnis untuk memperoleh keuntungan yang besar. Keberhasilan tersebut sangat tergantung kepada sumber daya manusia sebagai pelaku bisnis yang menjalankan roda perusahaan dengan ilmu pengetahuan yang dimiliki. Meng-hijack karyawan dari kompetitor merupakan salah satu cara tercepat untuk mendapatkan sumber daya manusia yang berkualitas dan siap pakai. Tingkat Turnover karyawan yang sangat tinggi maka sangat diperlukan knowledge management perusahaan untuk menghindari hilangnya pengetahuan perusahaan. Dibutuhkan transfer knowledge antara karyawan untuk proses pekerjaan berkelanjutan. Implementasi KMS berbasis website diharapkan dapat menjadi solusi dari kebutuhan untuk berbagi pengetahuan yang tidak dihalangi oleh batasan waktu dan lokasi geografis. Implementasi aplikasi website dengan menggunakan model spiral diharapkan bisa mempercepat proses pembuatan karena didalamnya terdapat tahapan pembuatan prototipe aplikasi yang bisa divalidasi oleh user secara langsung dan memberikan feedback untuk perbaikan. Aplikasi KMS ini menghasilkan Forum Discussion Group, Manual Guide, Tutorial, Tips \& Trick, Article, e-SOP, Archive Project, Search Knowledge. Diharapkan bisa sebagai media/sarana untuk penciptaan pengetahuan, berbagi pengetahuan serta transfer pengetahuan sehingga pengetahuan atau tingkat keahlian karyawan akan meningkat.
\end{abstract}

Kata Kunci: Manajemen, pengetahuan, berbagi, transfer, forum, diskusi, tutorial.

\section{PENDAHULUAN}

Perusahaan berskala besar maupun kecil mempunyai Standard Operational Procedure (SOP) dalam menjalankan kegiatannya. Dokumen SOP bagi perusahaan bersifat rahasia oleh karena itu tidak semua karyawan bisa mendapatkan informasi tersebut secara bebas. Sebuah perusahaan dalam menjalankan operasionalnya pasti dihadapkan dengan permasalahan, besar kecilnya permasalahan tergantung dari perusahaan bagaimana mengkategorikan sebuah permasalahan dan cara menyelesaikan permasalahan itu sendiri.

PT. Trans Retail Indonesia adalah salah satu perusahaan retail besar yang beroperasi di Indonesia dengan merek dagang "Transmart /Carrefour". Memiliki banyak gerai yang tersebar di 28 kota lebih di seluruh Indonesia. (sumber: http://www.carrefour.co.id). Gerai yang tersebar di beberapa kota akan menghadapi keterlambatan dalam penyebaran pengetahuan perusahaan. Memiliki karyawan dengan jumlah banyak, pertukaran dan perpindahan antar departemen, dan keluar masuk karyawan dari perusahaan memerlukan waktu dan biaya dalam mentransfer pengetahuan perusahaan. Kegiatan dalam menciptakan pengetahuan perusahaan merupakan langkah yang dilakukan untuk inovasi yang berkelanjutan (James A O'Brien \& George M Marakas:57)

Knowledge management adalah gabungan atau integrasi pengalaman, nilai, informasi, nilai dan pendapat para pakar. Komponen yang mendukung knowledge management adalah kebutuhan praktis, kecepatan, kompleksitas, evolusi dan knowledge (mengetahui apa yang belum 
diketahui). Knowledge management diharapkan mampu mempercepat sharing knowledge (berbagi pengetahuan) dengan orang lain dengan cara merubah Tacit Knowledge menjadi Explicit Knowledge.

Perpindahan karyawan antar perusahaan retail merupakan hal yang sering terjadi. Kompetitor melalukan perekrutan secara langsung kepada karyawan yang sudah bekerja di perusahaan retail dengan memberikan penawaran penghasilan lebih tinggi dari perusahaan sekarang bekerja (hijack). Tingginya angka tingkat pergantian karyawan pada posisi tertentu bisa mempengaruhi kinerja perusahaan apalagi terjadi pada bagian operasional. Keluarnya karyawan membawa informasi dan pengetahuan (knowledge) yang sangat penting dan itu merupakan asset perusahaan. Permasalahan yang sering terjadi, cara penanganan permasalah, pekerjaan yang belum terselesaikan, rencana pekerjaan selanjutnya dan lain sebagainya yang seharusnya ditransfer/share ke karyawan pengganti lainnya. Dengan hilangnya karyawan tersebut berarti hilang juga informasi dan pengetahuan perusahaan. Hal ini sangat merugikan perusahaan itu sendiri karena bisa mengganggu jalannya operasional perusahaan.

Perusahaan memerlukan kaderisasi untuk posisi atau jabatan penting tertentu dengan berbagi pengetahuan (knowledge sharing) antar karyawan sebagai salah satu cara untuk mencegah hilangnya pengetahuan perusahaan. Membutuhkan waktu lama dalam mencari dokumen penting perusahaan dengan menggunakan media konvensional (media kertas) sehingga membutuhkan media penyimpanan dalam merekam kejadian /permasalahan perusahaan (troubleshooting) dalam bentuk elektronik/digital.

Sistem manajemen pengetahuan (Knowledge Management System) perusahaan harus bisa diakses dengan mudah dan tanpa batasan waktu. Salah satu protokol yang bisa digunakan dan mendukung adalah HTTP (Hypertext Transfer Protocol). Knowledge Management System dengan berbasis website bisa diimplimentasikan dengan jaringan intranet perusahaan yang bisa diakses oleh seluruh karyawan tanpa spesifikasi hardware yang tinggi. Knowledge management tersebut pada akhirnya dapat menjadi dukungan yang handal bagi perusahaan untuk meningkatkan daya saing.
Banyaknya model pengembangan software yang bisa dipakai dalam membangun sebuah aplikasi salah satunya adalah model Spiral. Model Spiral digunakan untuk menyelesaikan sistem secara global kemudian untuk feature/kelebihan/keistimewaan dari sistem akan dikembangkan selanjutnya. Hal ini mempercepat dalam proses implementasi project dan cocok digunakan dalam sistem informasi berbasis website

\section{METODE PENELITIAN Tinjauan Studi}

Penelitian yang dilakukan oleh Putri Suhitarini Soemarto dan Togar Harapan Pangaribuan dari seminar nasional aplikasi teknologi informasi 2009 yang berjudul "Knowledge Management System: Knowledge Sharing Culture di Dinas Sosial Provinsi DKI Jakarta" diperoleh bahwa KMS dapat menumbuh kembangkan inovasi, memudahkan untuk mengelola knowledge tacit dan explicit karena knowledge tersimpan dalam benutk digital dan lebih terstruktur sehingga proses pencarian knowledge lebih cepat. Setiap pegawai dapat mengeksplisitkan

semua tacit knowledge yang dimiliki sehingga dapat disebarluaskan melalui media portal KMS kepada pegawai lain. Untuk membangun budaya kreatif, inovatif dan mau melakukan knowledge sharing perlu didukung teknologi yang memadai. Perkembangan opensource web platform memungkinkan implementasi knowledge management portal ke dalam bentuk yang lebih sederhana namun cukup membantu setiap pegawai mengeksplorasi dan mengembangkan knowledge serta menjembatani terjadinya knowledge sharing culture (Putri Suhitarini, 2009).

\section{Knowledge Managemet System}

Thomas Davenport mendefinisikan bahwa "Knowledge merupakan campuran dari pengalaman, nilai, informasi konstektual, pandangan pakar dan instuisi mendasar yang memberikan suatu lingkungan dan kerangka untuk mengevaluasi dan menyatukan pengalaman baru dengan informasi. Di perusahaan knowledge sering terkait tidak saja pada dokumen atau tempat penyimpanan barang berharga, tetapi juga pada rutinitas, proses, praktek dan norma perusahaan" (Davenport, 2001:23). 
Knowledge dibagi menjadi dua jenis yaitu Explicit Knowledge dan Tacit Knowledge, yang dapat dijabarkan sebagai berikut (Wahono, 2006:4).

1. Explicit Knowledge: adalah knowledge tertulis, terarsip, tersebar (cetak maupun elektronik) diekspresikan dengan katakata dan angka, serta dapat disampaikan dalam bentuk ilmiah, spesifikasi atau manual dan bisa sebagai bahan pembelajaran (reference) untuk orang lain.

2. Tacit Knowledge: adalah knowledge dari para pakar baik individu maupun masyarakat yang berbentuk know-how, pengalaman, skill, pemahaman, maupun petunjuk prakits (rules of thumb) berada didalam benak orang yang mengetahui.

Menurut SECI Model ada empat proses kejadian dalam transfer pengetahuan, yaitu (Pirambodo, 2010:2):

1. Socialization (tacit ke tacit), adalah proses transfer informasi diantara orang-orang dengan cara conversation /percakapan.

2. Externalization, yaitu transfer dari tacit knowledge ke explicit knowledge

3. Combination, adalah transfer dari explicit knowledge ke explicit knowledge.

4. Internalization, adalah transfer dari explicit knowledge ke tacit knowledge.

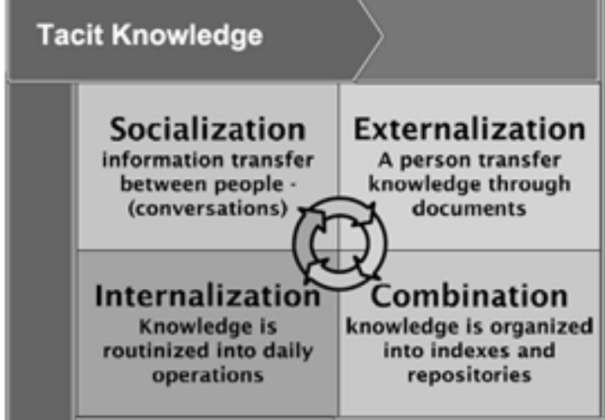

Explicit Knowledg

Gambar 2.1 Model SECI (Priambodo 2010:2)

\section{Software Development Life Cycle (SDLC) Model Spiral}

Pengembangan perangkat lunak dengan pendekatan Spiral merupakan penggabungan antara metodologi waterfall dan metodologi prototype dengan upaya memadukan keunggulan diantara keduanya.

Didefinisikan pertama kali oleh Barry Boehm pada artikelnya "A Spiral Model of
Software Development and Enhancement" di tahun 1986. Model ini memiliki tahap-tahap umum sebagai berikut (Sommerville, 2010:49):

1. Objective setting atau penentuan tujuan, kebutuhan sistem dijelaskan sedetail mungkin sampai dengan analisa resiko.

2. Risk assessment dan reduction, mengidentifikasikan dan memecahkan masalah, proses desain sistem, merupakan tahap paling penting dalam model ini, karena merupakan permulaan dan penanganan masalah secara keseluruhan sehingga dapat menghemat biaya pengembangan.

3. Development and validation, pengembangan dan pengujian purwa-rupa sistem.

4. Planning, perencanaan pengulangan tahap untuk memperbaiki purwa-rupa yang telah dibuat sehingga menjadi sistem yang siap pakai dan sesuai dengan kebutuhan.

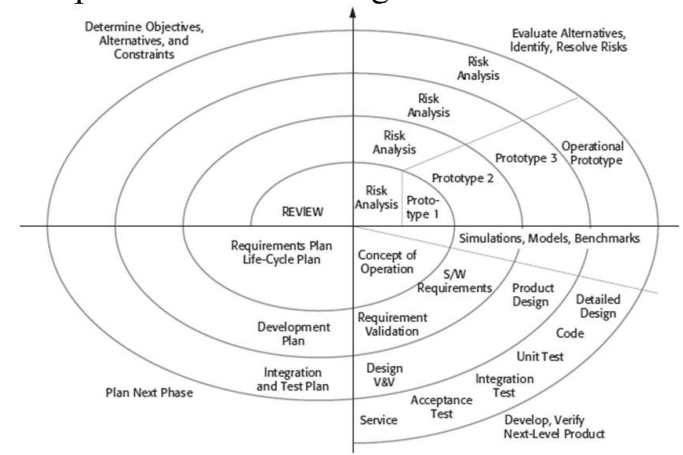

Gambar 2.2 Boehm's Spiral Model (Sommerville, 2010:49)

Dari gambar tersebut, proses dimulai dari inti bergerak searah dengan jarum jam mengelilingi spiral. Lintasan pertama putaran menghasilkan perkembangan spesifikasi produk. Putaran selanjutnya digunakan untuk mengembangkan sebuah prototype, dan secara progresif mengembangkan versi perangkat lunak yang lebih canggih. Masing-masing lintasan yang melalui perencanaan menghasilkan penyesuaian pada perencanaan proyek. Biaya dan jadwal disesuaikan berdasarkan umpan balik yang disimpulkan dari evaluasi pelanggan. Manajer proyek akan menambah jumlah iterasi sesuai dengan yang dibutuhkan.

\section{Mind Map}

Mind map adalah cara termudah untuk menempatkan informasi ke dalam otak dan 
mengambil informasi ke luar kotak. Mind map adalah cara mencatat yang kreatif, efektif dan secara harfiah akan "memetakan" pikiranpikiran kita. Mind map juga sangat sederhana (Buzan, Buku Pintar Mind Map, 2007:5).

Mind map merupakan peta rute yang hebat bagi ingatan, memungkinkan kita menyusun fakta dan pikiran sedemikian rupa sehingga cara kerja alami otak dilibatkan sejak awal. Dengan mind map, daftar informasi yang panjang bisa dialihkan menjadi diagram warnawarni, sangat teratur, dan mudah diingat dengan cara kerja alami otak dalam melakukan berbagai hal.

Mind map dapat membantu kita dalam banyak hal, diantaranya: merencanakan, berkomunikasi, menjadi lebih kreatif, menghemat waktu, menyelesaikan masalah, memusatkan perhatian, menyusun dan menjelaskan pikiran-pikiran, mengingat dengan lebih baik, belajar lebih cepat dan efisien, melihat gambar secara keseluruhan.

\section{PEMBAHASAN}

\section{Analisa Kebutuhan Data}

Analisa kebutuhan data yang diperlukan dalam Knowledge Management Sytem diantaranya adalah User sebagai pengguna yang akan menggunakan, Administrator selaku pengguna yang memiliki hak penuh untuk mengatur berjalannya sistem, Moderator selaku pengguna yang memiliki hak khusus untuk memasukan knowledge khusus, Knowledge dalam bentuk standar operasional prosedur, manual guide, dokumen troubleshooting, forum diskusi, hasil meeting dan Report.

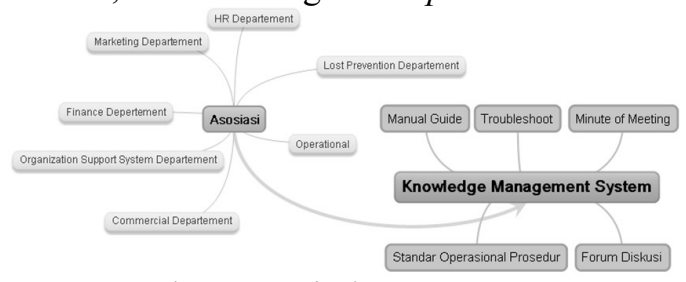

Gambar 3.1 Mind Maps KMS

\section{Analisa Sistem Usulan}

Knowledge Management System merupakan solusi dari permasalahan dalam mengelola pengetahuan perusahaan. Sharing/transfer knowledge dan forum diskusi bisa dijadikan sebuah pengetahuan.

Sharing knowledge antar karyawan dipertemukan dalam satu tempat yaitu knowledge management system, sehingga dalam proses penyebaran pengetahuan jauh lebih cepat ke seluruh cabang perusahaan diberbagai kota dan bisa diakses kapanpun dan dimanapun dalam ruang lingkung jaringan perusahaan.

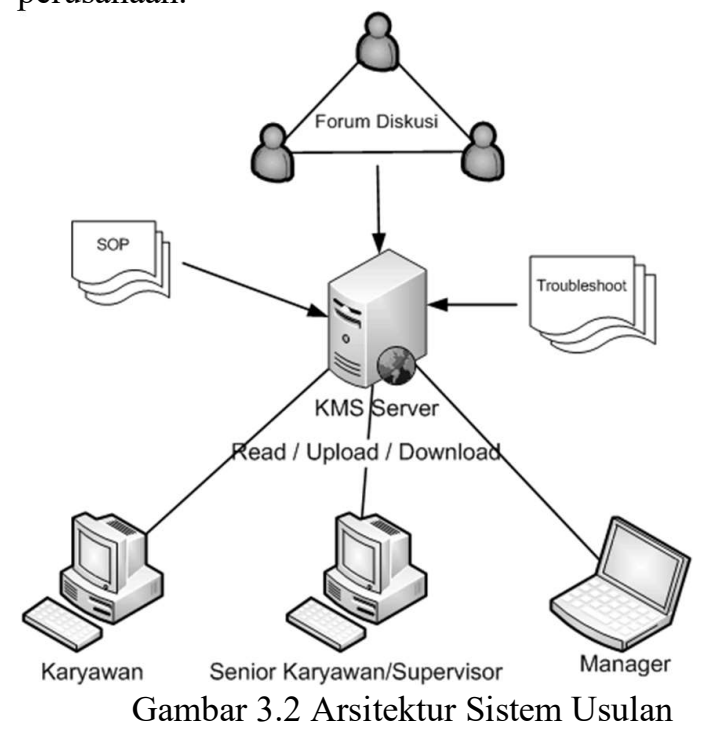

\section{Tahapan Penilitan}

Model yang digunakan dalam pembuatan sistem ini adalah model Spiral. Model ini adalah penggabungan antara model waterfall dan model prototype. Berikut adalah tahapan penelitian yng telah disesuaikan dengan model spiral:

1. Determine objective, membutuhkan sebuah sistem untuk mengelola pengetahuan. Sistem tersebut digunakan sebagai sarana atau media pertukaran pengetahuan dan penyimpanan dokumen perusahaan.

2. Identify and resolve risk, analisa kebutuhan pembuatan sistem, perancangan sistem dan perancangan database KMS.

3. Development and test, pembuatan sistem KMS sesuai perancangan dengan membuatkan prototype untuk dilakukan pengujian oleh business user secara bertahap.

4. Plan the next iteration, hasil dari pengujian prototype merupakan masukkan untuk memperbaiki kekurangan dan mengulangi ke tahap berikutnya sehingga sistem siap pakai dan sesuai dengan kebutuhan setelah semuanya melewati pengujian dan proses UAT (User Acceptance Test).

\section{Pembahasan}


Tahapan pengembangan software dengan model spiral dalam 1 putaran meliputi Objective Setting, Risk Assesment and Reduction, Development and Validation dan Planning.

Pelaku dalam Knowledge Management System meliputi:

1. Administrator, karyawan yang ditugaskan untuk mengatur secara keseluruhan berjalannya KMS meliputi menentukan profile user, pemberian hak terhadap modulmodul yang tersedia, memelihara dan mengatur knowledge yang ada.

2. Supervisor/Manager, karyawan yang ditugaskan untuk mentransfer knowledge dari tacit menjadi explicit, membuat dan memelihara Standard Operationg Procedure (SOP) dan membuat dokumentasi project.

3. User, seluruh karyawan selain profile sebelumnya. Transfer knowledge dari explicit menjadi tacit. Mencari dan mempelajari knowledge yang tersedia.

Model Spiral Putaran Pertama

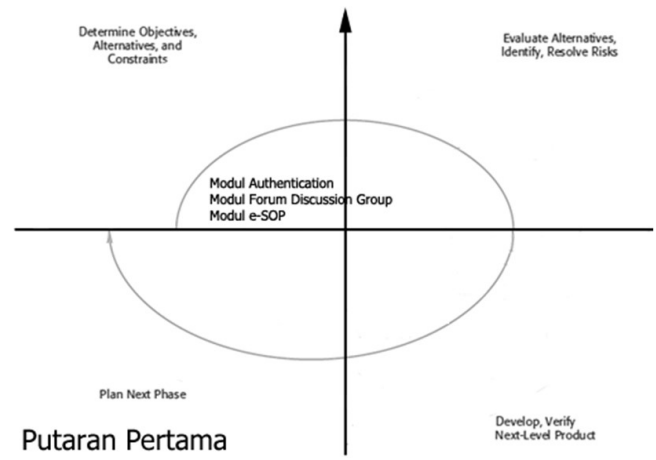

Gambar 3.3 Model Spiral putaran pertama Objective Setting

Modul yang akan dibangun pada putaran pertama ini sebanyak 3 modul yang terdiri dari modul authentication, forum discussion group dan electronic standard operating procedure.

\section{Risk Assesment and Reduction}

Dari ketiga modul yang akan dibangun sangat memungkinkan untuk dilanjutkan ke tahap development karena modul-modul tersebut merupakan kebutuhan utama dari knowledge management system. Resiko yang bisa menghambat nantinya adalah terdapat pada modul e-SOP yaitu pada saat konversi dari bentuk konvensional menjadi elektronik karena masih dilakukan secara manual dengan menscan dokumen SOP.

\section{Development and Validation}

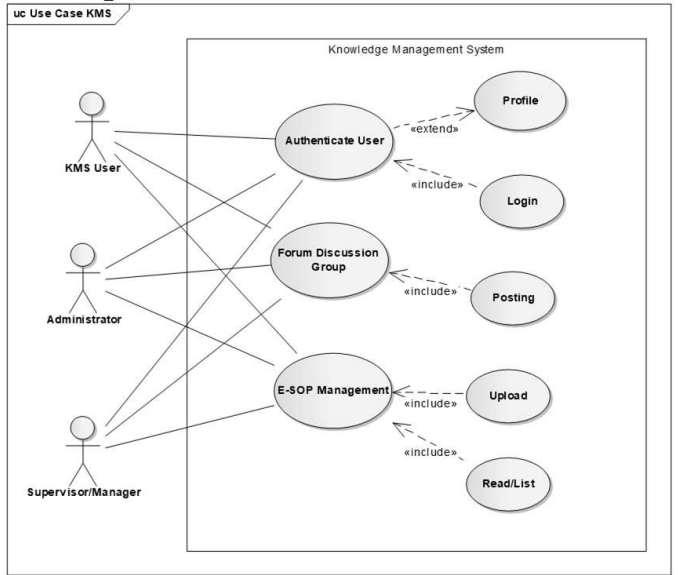

Gambar 3.4 Use case putaran pertama

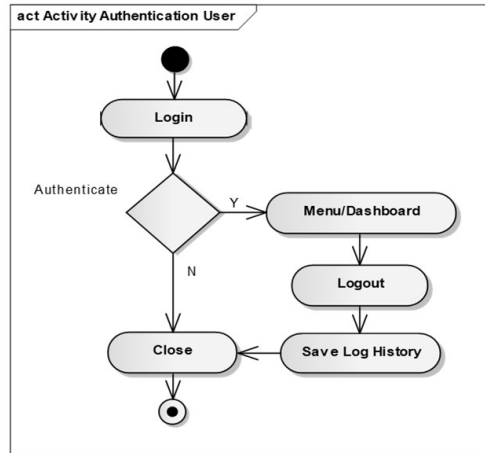

Gambar 3.5 Activity authentication

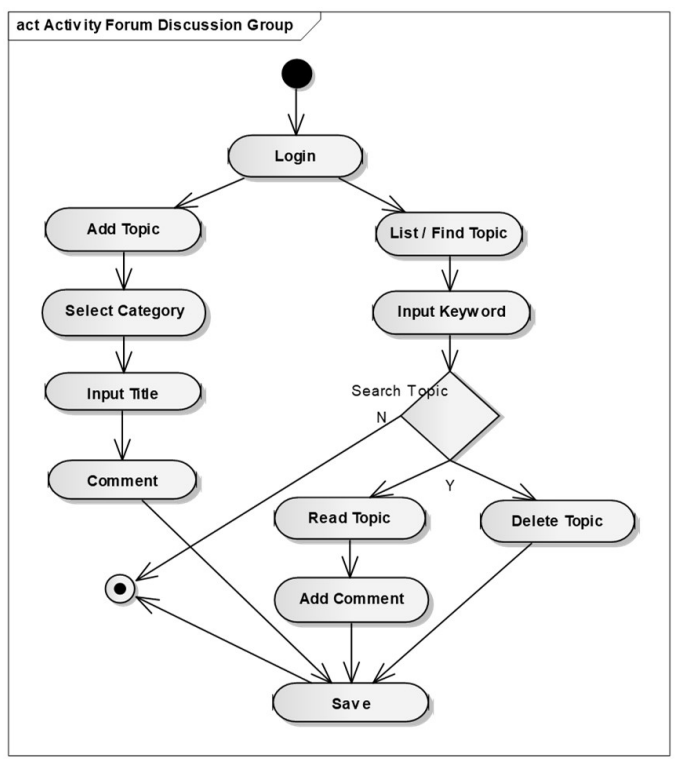


Gambar 3.6 Activity forum discussion group

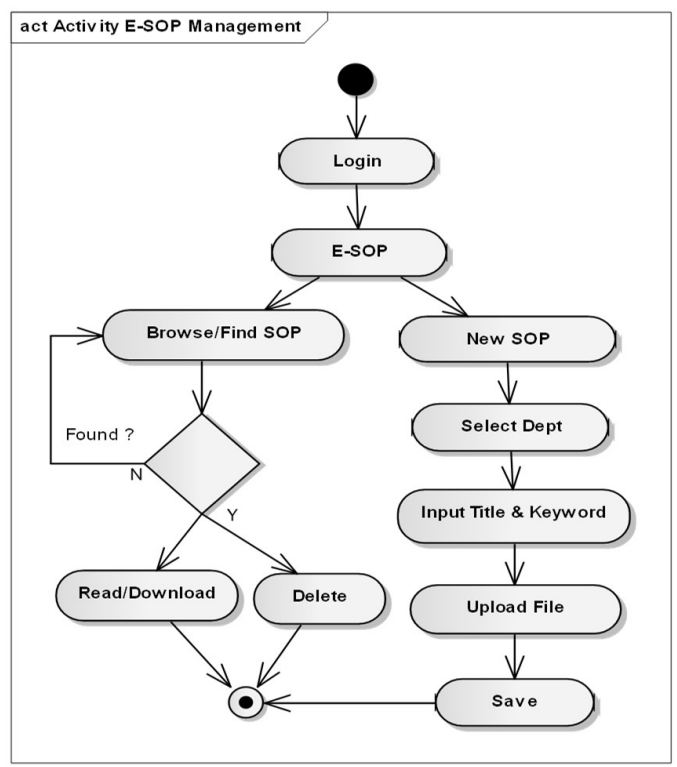

Gambar 3.7 Activity e-SOP

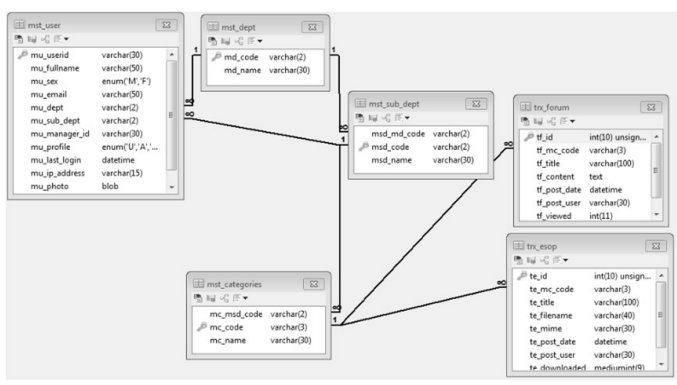

Gambar 3.8 ERD putaran pertama

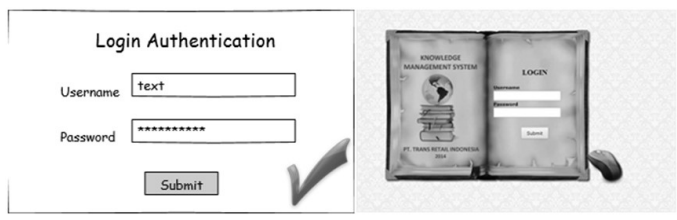

Gambar 3.9 Design UI \& Validation authentication

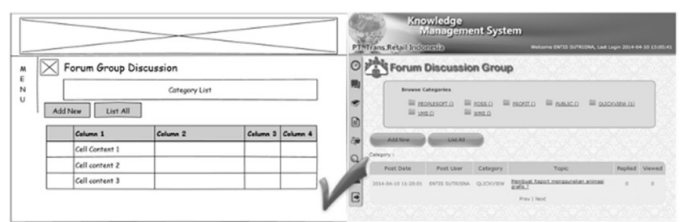

Gambar 3.10 Design UI \& Validation FDG

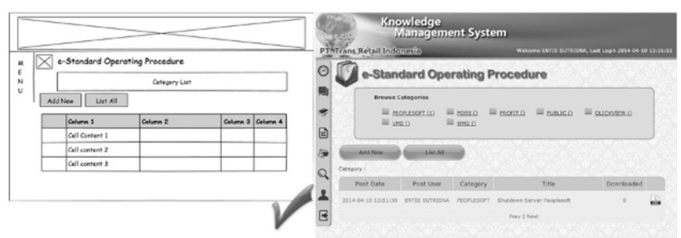

Gambar 3.11 Design UI \& Validation e-SOP Planning

Modul selanjutnya yang akan dibangun adalah modul knowledge base untuk membantu sharing knowledge lainnya selain Forum Discussion Group dan e-SOP.

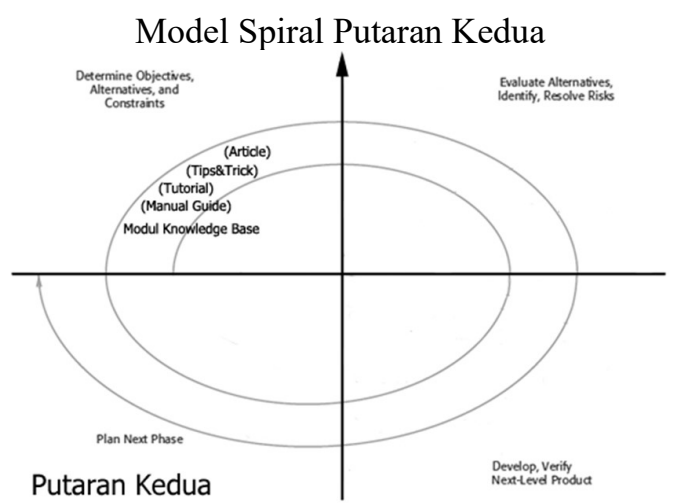

Gambar 3.12 Model spiral putaran kedua Objective Setting

Media yang bisa dipakai untuk berbagi pengetahuan perusahaan lainnya adalah berbagi buku panduan (manual guide) pekerjaan, berbagi tutorial, berbagi tips \& triks dan berbagi artikel perusahaan.

Dokumentasi buku panduan (manual guide) biasanya diperoleh dari vendor pada saat penutupan sebuah project atau membeli sebuah produk. Dokumen tutorial merupakan bagian kecil dari manual guide. Dokumen ini biasanya lebih spesifik ke masalah tertentu dan biasanya dilakukan dengan tahap demi tahap sehingga kesalahan sangat sedikit dijumpai. Dokumen tips \& triks merupakan tambahan diluar manual guide dan tutorial. Pengetahuan ini biasanya ditemukan pada saat implementasi sistem sudah berjalan dan sebagai pengguna terkadang menemukan alternatif lain untuk mempercepat proses. Artikel pengetahuan secara umum bisa disebarluaskan ke karyawan lain karena tidak semua karyawan bisa memanfaatkan waktu luang untuk mengembangkan diri dengan mencari pengetahuan diluar perusahaan yang bisa mendukung dengan pekerjaannya.

\section{Risk Assesment and Reduction}

Keempat modul tersebut tiga diantaranya secara konsep mempunyai kesamaan yaitu manual guide, tutorial dan tips \& trick. Perbedaan dari ketiga modul tersebut terletak pada isi dari dokumen. 
Pada saat implementasi, resiko yang bisa dikhawatirkan adalah salah penempatan dokumen akan tetapi seiring nanti berjalannya sistem dan kebiasaan user akan paham dengan sendirinya.

\section{Development and Validation}

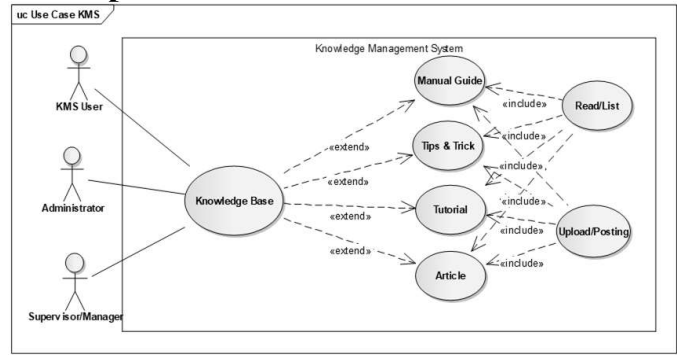

Gambar 3.13 Use case putaran kedua

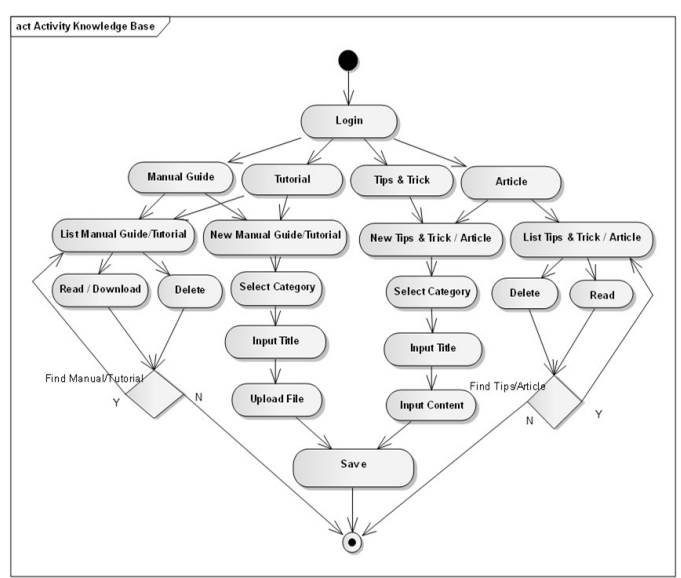

Gambar 3.14 Activity knowledge base

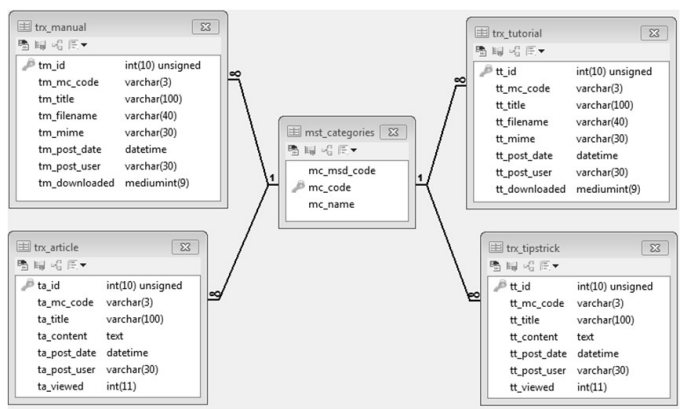

Gambar 3.15 ERD putaran kedua

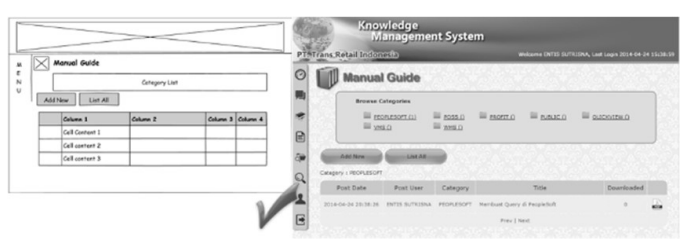

Gambar 3.16 Design UI \& validation manual guide

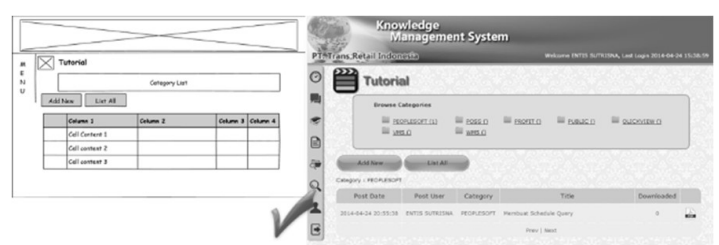

Gambar 3.17 Design UI \& validation tutorial

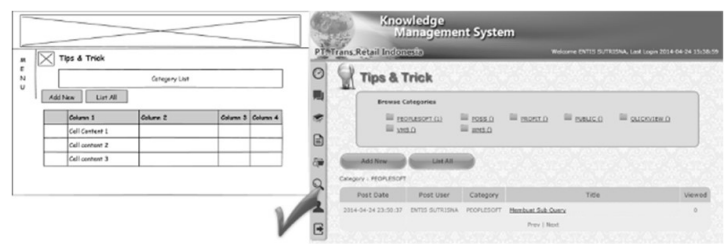

Gambar 3.18 Design UI \& validation tips \& tricks

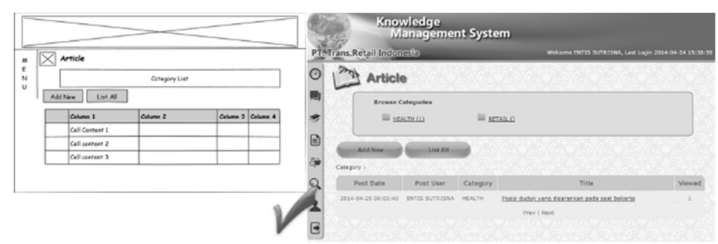

Gambar 3.19 Design UI \& validation article Planning

Modul selanjutnya yang akan dibangun adalah modul search knowledge, archive project dan dashboard untuk membantu memudahkan dan mempercepat pencarian dokumen pengetahuan.

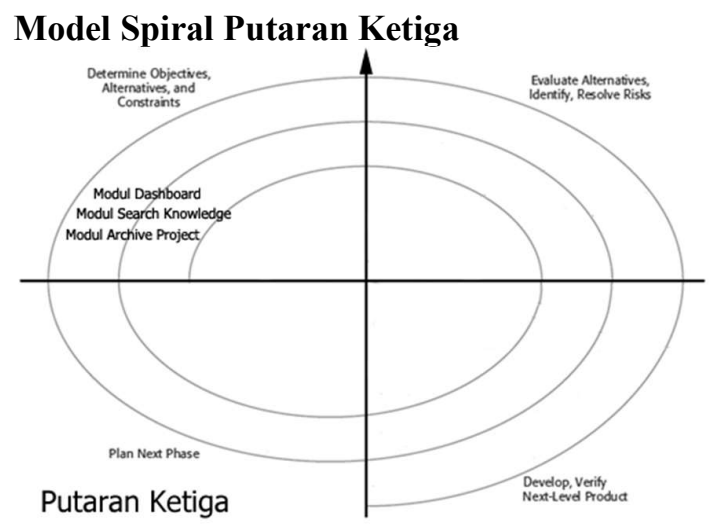

Gambar 3.20 Model spiral putaran ketiga Objective Setting

Memudahkan pencarian dokumen dan kecepatan waktu dalam mendapatkan dokumen merupakan fitur utama yang harus ada dalam Knowledge Management System. Modul yang akan dibangun pada putaran ketiga ini adalah dashboard, archive project dan search knowledge. 


\section{Risk Assesment and Reduction}

Modul dashboard dan modul search knowledge merupakan modul yang harus tersedia karena modul tersebut sangat penting apabila jumlah dokumen pengetahuan sudah semakin banyak.

Modul archive project resiko kemungkinan pada saat implementasi sudah berjalan, project manager tidak mengisi form pada saat closing project. Hal ini bisa diatasi dengan meminta bantuan kebijakan dari top management untuk mewajibkan mengisi form tersebut.

\section{Development and Validation}

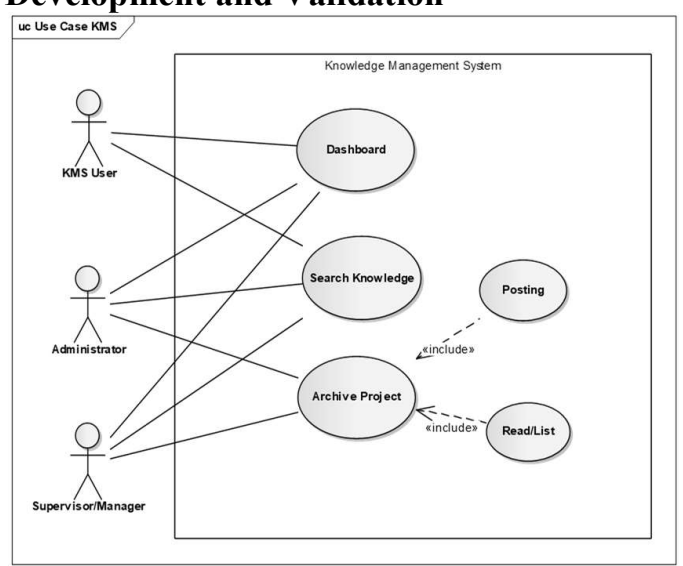

Gambar 3.21 Use case putaran ketiga

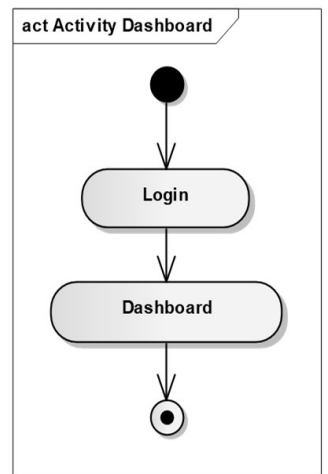

Gambar 3.22 Activity dashboard

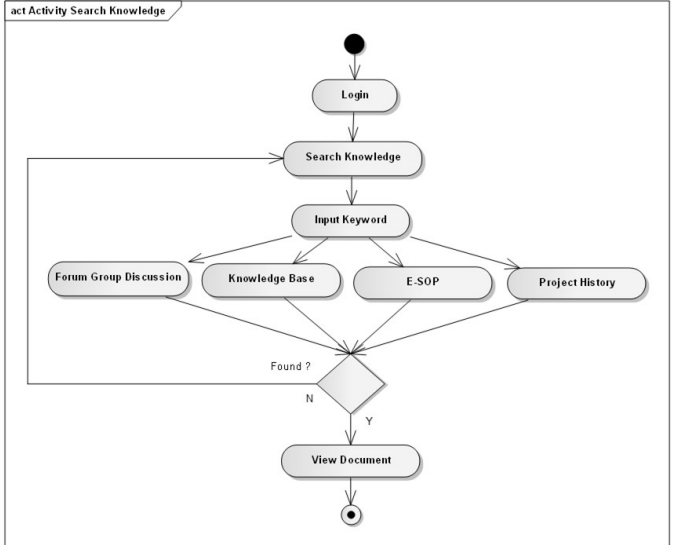

Gambar 3.23 Activity search knowledge

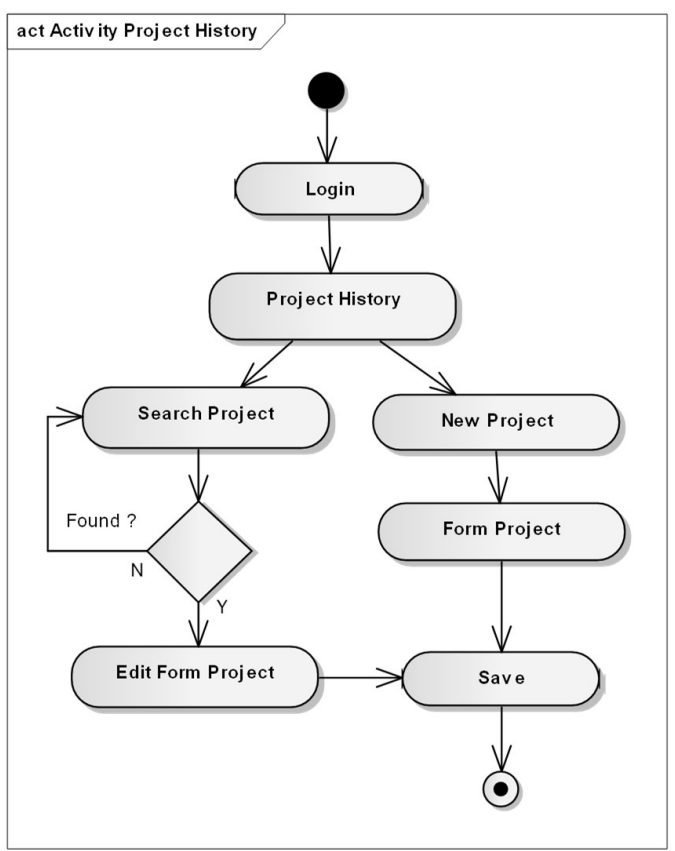

Gambar 3.24 Activity project history

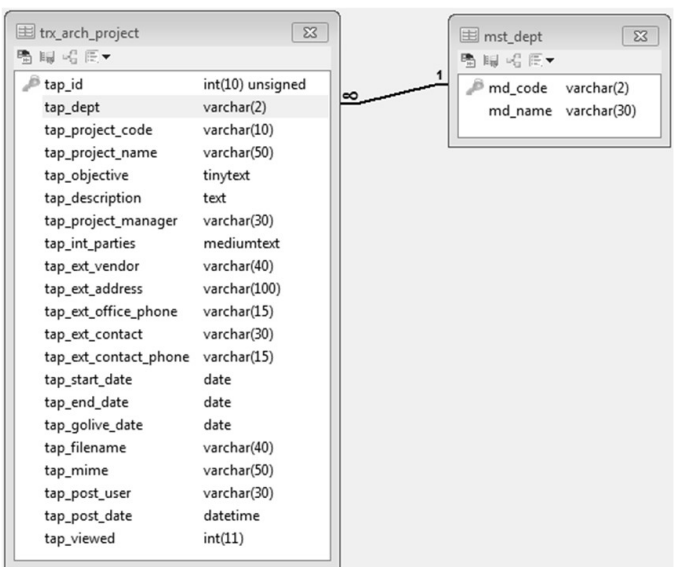

Gambar 3.25 ERD putaran ketiga 


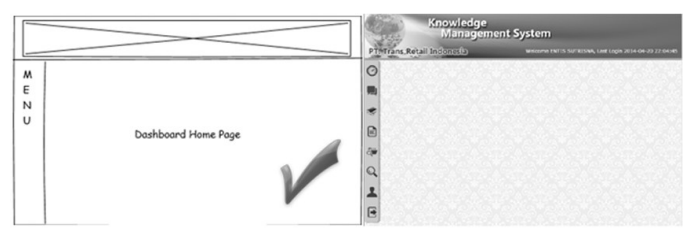

Gambar 3.26 Design UI \& validation dashboard

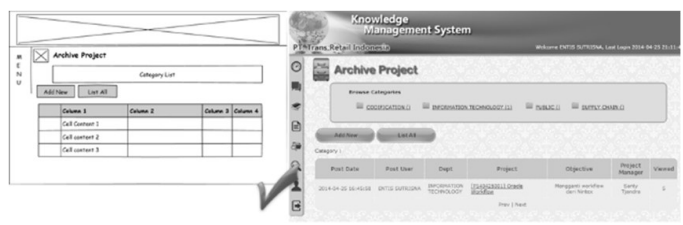

Gambar 3.27 Design UI \& Validation archive project Planning

Hasil secara keseluruhan dari validasi dan pengujian prototipe pada putaran ketiga ini sesuai dengan rancangan dan menjawab kebutuhan bisnis sebagai solusi dari permasalahan.

\section{Integration}

Ketiga tahapan pengembangan model spiral dilakukan penggabungan untuk menjadi satu kesatuan aplikasi sistem dan mengetahui kemungkinan resiko kesalahan setelah penggabungan.

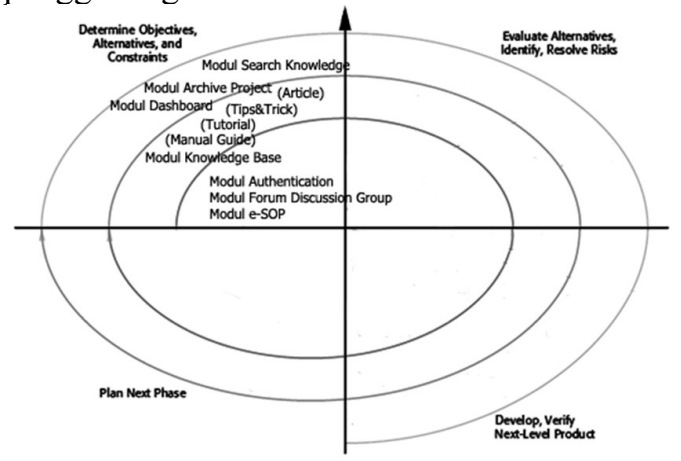

Gambar 3.28 Gabungan model spiral 3 putaran

Modul-modul setelah digabungkan berdasarkan urutan menu yang akan ditampilkan.

1. Authentication

2. Dashboard

3. Forum discussion group

4. Knowledge base: manual guide, tutorial, tips \& tricks dan article

5. e-SOP

6. Archive project

7. Search knowledge

\section{IMPLEMENTASI}

Environment yang harus disiapkan sebelum melakukan tahap implementasi sehingga proses berjalan tanpa ada hambatan baik itu dari sisi komputer server aplikasi ataupun komputer client.

\section{Server Side}

Sistem operasi yang digunakan pada komputer server menggunakan berbasis Linux open source yaitu Centos versi 5.0 atau diatasnya. Software pendukung lainnya yang menunjang diantaranya:

Web server. Apache versi 2.0 atau diatasnya. Database server. Teknologi database yang digunakan MySQL server community versi 5.0 atau diatasnya

Programming language. PHP versi 5.1.4 atau diatasnya. Pastikan web server sudah mengenal bahasa PHP dan PHP sudah mendukung fungsi database MySQL.

\section{Client Side}

Sistem operasi yang digunakan untuk komputer client tidak ditentukan selama sistem operasi tersebut mendukung Graphic User Interface (GUI) dan terhubung dengan jaringan komputer (LAN). Software pendukung yang harus tersedia di komputer client adalah browser yang sudah mendukung HTML 5.

\section{KESIMPULAN}

Berdasarkan hasil pembahasan yang telah dilakukan dapat ditarik kesimpulan bahwa penerapan knowlodge management system berbasis website dengan model Spiral pada PT. Trans Retail Indonesia dapat dilakukan dengan tiga putaran model Spiral.

Gabungan dari ketiga putaran tahapan model Spiral ini menghasilkan modul authentication, forum discussion group, e-SOP, knowledge base, search knowledge, archive project dan dashboard.

Dengan melakukan ketiga putaran model Spiral maka aplikasi knowledge management system pada PT. Trans Retail Indonesia dapat diterapkan dan menghasilkan diantaranya:

1. Media / sarana untuk berbagi pengetahuan antara karyawan sebagai proses kaderisasi melalui forum diskusi, manual guide, tutorial dan standar operasional prosedur.

2. Pencarian dokumen pengetahuan perusahaan lebih cepat dan terstruktur.

3. Tersedia media penyimpanan untuk merekam segala permasalahan perusahaan 
beserta pemecahannya yang bisa dijadikan sebagai perpustakaan digital.

\section{DAFTAR PUSTAKA}

[1] Agarwal, S.P Tayal, M. Gupta, (2010), "Software Engineering \& Testing", p46, ISBN 978-1-934015-55-1

[2] Andrawina, et al., (2008), Hubungan antara Knowledge Sharing Capability, Absorptive Capacity dan Mekanisme Formal: Studi Kasus Industri Teknologi Informasi dan Komunikasi di Indonesia, Jurnal Teknik Industri Vol. 10, No. 2, Desember 2008, Istitut Teknologi Telkom.

[3] Barry W. Boehm, (1988), A Spiral Model of Software Development and Enhancement

[4] Bogdan dan Biklen, (2010), "Qualitative Research For An Introduction The Teory and Method", London

[5] Buzan, (2007), T. Buku Pintar Mind Map. Jakarta: Gramedia Pustaka Utama

[6] Davis, Gordon B., (1999), Kerangka Dasar Sistem Informasi Manajemen Bagian I, PT. Pustaka Binaman Pressindo, Jakarta.

[7] Davenport, Thomas H and Prusak L, (2001), Working Knowledge : How Organization Manage What They Know. Boston : Harvard Business School Press

[8] Dhote, Prajakta C., and Chandrakant N. Dhote., (2012), "Application Of Knowledge Management in Education Industry", International Journal of Information Technology and Knowledge Management, JanuaryJune 2012, Volume 5, No. 1, pp.37-39

[9] Estriyanto, et al., (2008), Implementasi Knowledge Management pada APTEKINDO, Pembentukan Sharing Culture antar Pendidikan Teknologi dan Kejuruan di Indonesia, Konvensi Nasional IV APTEKINDO.

[10] Hartono, Jogiyanto, (2002), Analisa Disain Sistem Informasi, Penerbit Andi, Yogyakarta.

[11] Ho, Lim Bui, Bawa Wuryaningtyas, Ronald, dan Richard Kumaradjaja, (2008), "Penerapan Knowledge Management System pada Perusahaan Bisnis Konsultasi PT Piramedia
Sejahtera Abadi (Red Piramid)", Jurnal Piranti Warta Vol. 11 No. 3 Agustus 2009; p451-468, ISSN: 14412221

[12] Irawanto, (2007), "Strategi Pengembangan Kapasitas SDM melalui Knowledge Management $(K M)$,, Journal Aplikasi Manajemen, Volume 5, Nomor 3, Desember 2007, p 380-385

[13] James A. O'Brien, George M Marakas, (2006), "Management Information Systems" seventh edition, p 57, ISBN 0-07-111629-X

[14] Kosasih, Natalia dan Sri Budiani, (2007), "Pengaruh Knowledge Management Terhadap Kinerja Karyawan: Studi Kasus Departemen Front Office Surabaya Plaza Hotel”, Junal Manajemen Perhotelan, Vol. 3 No. 2 September 2007, p 80-88, ISSN: 0216-6283

[15] Metaxiotis, Kostas, (2010), Intelligent Information Systems and Knowledge Managemen for Energy, National Technical University of Athens, Greece

[16] Mcleod, Raymond, Jr., dan Schell, George P. (2007). Management Information Systems (10th Edition). New Jersey: Pearson Educatoin, inc.

[17] Mc. Leod, Raymond Jr., (2001), Sistem Informasi Manajemen Jilid 1, PT. Prenhallindo, Jakarta.

[18] Priambada, Boy Dewa (2010), Implementasi Knowledge Management System di Perusahaan, Program Pasca Sarjana Ilmu Komputer IPB.

[19] Putri, Suhitarini Soemarto, dan Togar Harapan Pangaribuan, (2009), "Knowledge Management System: Knowledge Sharing Culture di Dinas Sosial Provinsi DKI Jakarta", seminar nasional aplikasi teknologi informasi 2009 (SNATI 2009) ISSN: 1907-5022, Yogyakarta, 20 Juni 2009

[20] Roger Pressman and David Lowe, (2012), "Web Engineering A Practioner's Approach”, p13, ISBN 978-0-07-352329-3

[21] Rozaini Nasution, Prof., (2003), Teknik Sampling, Fakultas Kesehatan Masyarakat, Universitas Sumatera Utara 
[22] Safrizal, (2012) Knowledge Management System Berbasis Konsep Mind Map untuk Proses Knowledge Sharing di Universitas Satya Negara Indonesia, Jakarta, Tesis yang tidak dipublish di STMIK Eresha

[23] Sommerville, (2011), "Software Engineering $9^{\text {th }}$ Edition", p49, ISBN 978-0-13-703515-1

[24] Whitten, (2007), Systems Analysis \& Design Methods 7ed (hc), MC. Graw Hill

[25] Wahono, R. S. (2006) Knowledge Management dan Dunia Pendidikan : Studi kasus Ilmukomputer.com, UNPAD Bandung

[26] Yuliazmi, (2005), Penerapan Knowledge Management Pada Perusahaan Reasuransi Studi Kasus PT. Reasuransi Nasional Indonesia, Fakultas Pascasarjana Ilmu Komputer Universitas Budiluhur. 